\title{
A Way to Unlock The Electricity Energy Market for The Common People Using CP Model
}

\author{
Md. Maidul Islam ${ }^{1 *}$, Alimul Haque Khan², Md. Aman Khan ${ }^{3}$ \\ ${ }^{1}$ Electrical \& Electronic Engineering, Eastern University, Dhaka 1209, BANGLADESH \\ ${ }^{2}$ Electrical \& Electronic Engineering, University of Saskatchewan, CANADA \\ ${ }^{3}$ Electrical \& Electronic Engineering, Pabna University of Science \& Technology, Pabna, BANGLADESH \\ *Corresponding Contact: \\ Email: maidul.et@easternuni.edu.bd
}

\begin{abstract}
The electricity energy market is almost locked for the people. The trade of electric energy is defined as electricity energy market. In most of the countries, trade of $\mathrm{kWh}$ by the people is found very rare practice unlike other businesses. However, business related with energy and power equipment may be accomplished by individual if ones want. On the other hand, selling the $\mathrm{kWh}$ is somehow difficult. Few possible reasons that create resistance for a person to enter into electricity energy market such as the large size of power station, higher initial cost and lengthy procedures. This paper discusses the states the power of electricity market and proposes a way to unlock electricity energy market for people using CP (Consumer Producer) model. A way to widen the entry of electricity market may be the minimization of the size of the power station into very small unit which will have lower initial cost, quick as well as easy installation.
\end{abstract}

Key words

Consumer-producer uni, Unlock, Electricity market, people, trade of kWh

$12 / 15 / 2016$

Source of Support: None, No Conflict of Interest: Declared

This article is is licensed under a Creative Commons Attribution-NonCommercial 4.0 International License.

Attribution-NonCommercial (CC BY-NC) license lets others remix, tweak, and build upon work non-commercially,

and although the new works must also acknowledge \& be non-commercial.

\section{INTRODUCTION}

For a long time, the state ownership and heavy government regulation deregulates world electric-power sectors. The rules for competitive power market abuses the market power of electricity energy market. For long time, people have believed that power market is monopoly naturally. Consequently, all over the world state-owned monopolies or privately owned but heavily regulated monopolies covering often large geographic areas have dominated electric-power sectors. Today, people agree on the related to the forces of competition of generation and sale of electricity in market. The transition from monopolistic industry to competitive market must deal with the former franchise monopolies. The monopolies mean markets are typically dominated by one or a small number of producers. 
The prices will be lower if a large number of makers active in the market (Newbery, 1995). The standard method of decreasing market power is to increase the number of makers competing in the market. However, this might not lower the prices at all market locations if transmission capacity is limited (Newbery, 1995).

In 2010, global electricity generation was 21.5 billion MWh. In Jazz scenarios, this is expected to increase by $150 \%$ to 53.6 billion MWh by 2050. In Symphony scenarios, the increase will be about 123\% to 47.9 billion MWh by 2050 (Khan et al., 2015a). So, there will be a huge amount of investment to power sector all over the world at near future.Mainly three ways of generation and evacuation of electricity such as Grid connected, Micro grid, and Standalone which are not feasible for electricity market.

Since the early 21st century, opportunities to take advantage of improvements in electronic communication technology to resolve the limitations and costs of the electrical grid have become apparent. In the 21st century, some developing countries like China, India and Brazil are seen as pioneers of smart grid deployment. Growing concerns over environmental damage from fossil-fired power stations have led to a desire to incorporate significant amounts of renewable energy. In many literature reviews (Hunt and Shuttleworth, 1996; Agelidis et al., 2011) state necessities of having unlock the grid. In this paper, it has been proposed a straightforward way to unlock the power market for the people using new CP (Consumer Producer) model.

For creating the Micro grid in a safe and quick way which is supposed to be a prime factor in involving people in the trade of electrical energy design a new CP model.

\section{Power Market Analysis}

The situation of the power market in Bangladesh is discussed here. In the power sector, there are many areas to finance from the investors such as electricity generation, electricity transmission, and electricity distribution systems. Mainly public and private monopolies finance in the electricity generation, and people have no chance to incorporate in the trade of electricity generation in Bangladesh as well as other countries. Total net electricity energy (excluding REB) in fiscal year 2015 in Bangladesh was 43,738 GWh. Following table I shows the scenario of the power sector in Bangladesh.

Table 1: Power sector in Bangladesh at a glance

\begin{tabular}{|l|c|}
\hline Criteria & Amount \\
\hline Generation Capacity & 12,071 MW* (January, 2015) \\
\hline Highest Generation & 8,177 MW (13 August, 2015) \\
\hline Total Consumers & 17.8 Million (June, 2015) \\
\hline Transmission Line & 9,695 Ckt. km \\
\hline Distribution Line & $3,26,000 \mathrm{~km}$ \\
\hline Distribution Loss & $11.36 \%$ \\
\hline Per Capita Generation & $371 \mathrm{KWh}$ \\
\hline Access to Electricity & $74 \%$ \\
\hline
\end{tabular}

*Without captive \& SHS

Source: http://www.bpdb.gov.bd/download/annual_report

In Bangladesh, generation capacity is 12071 MW excluding generation from captive and SHS (Solar Home System) and total number of consumers is 17.8 Million. 


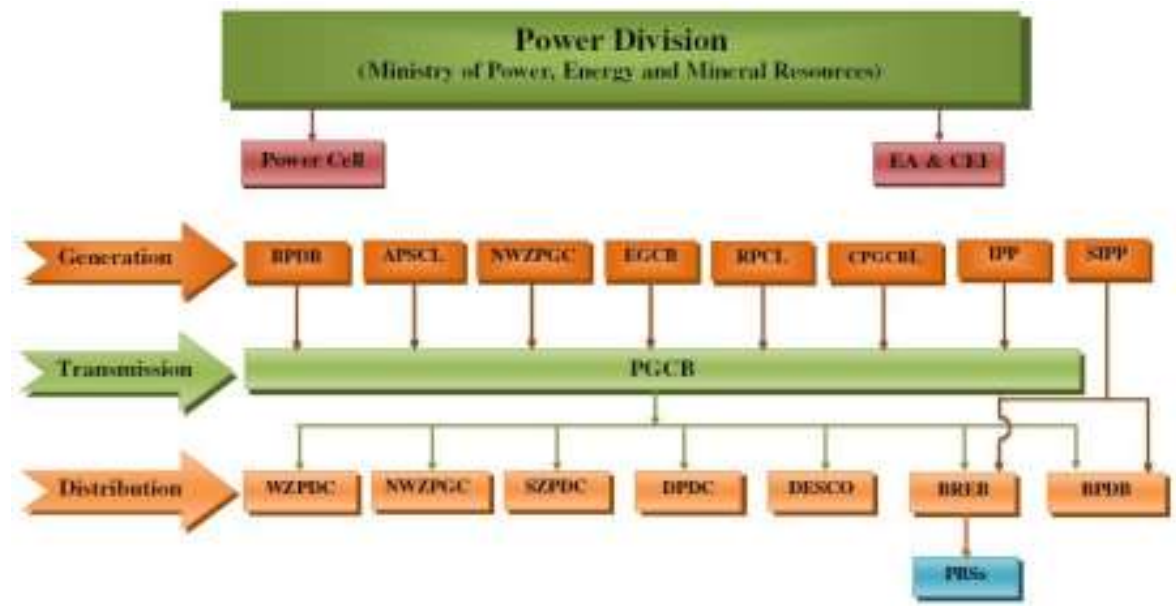

Figure 1: Power Sector Structure in Bangladesh

In Bangladesh, Power sector consists of three sub division as power generation, transmission, and distribution. Some public and private organizations are involved in generating power. Only an autonomous company, PGCB (Power Grid Company of Bangladesh) transmits power to distribution subsystem. Table 2 provides information on present generation capacity of the public and private sectors.

Table 2: Present Generation Capacity (November, 2013)

\begin{tabular}{|l|c|}
\hline Public Sector & Installed Generation Capacity(MW) \\
\hline BPDB & 4186 \\
\hline APSCL & 777 \\
\hline EGCB & 622 \\
\hline NWPGCL & 300 \\
\hline RPCL & 77 \\
\hline Subtotal & $5962(58 \%)$ \\
\hline Private sector & Installed Generation Capacity(MW) \\
\hline IPPs & 1655 \\
\hline Rental & 2096 \\
\hline Power Import & 500 \\
\hline Subtotal & $4251(42 \%)$ \\
\hline Total & 10,213 \\
\hline Sour &
\end{tabular}

Source: http:/ /www.powercell.gov.bd

Table 3: Estimated Financing Requirement for Generation Projects

\begin{tabular}{|l|c|c|c|}
\hline Description & $\begin{array}{c}\text { Total Investment } \\
\text { (M US\$) }\end{array}$ & $\begin{array}{c}\text { Equity } \\
\text { (M US\$) }\end{array}$ & $\begin{array}{c}\text { Debt } \\
\text { (M US\$) }\end{array}$ \\
\hline New initiatives 530 MW Rental projects & 424 & 106 & 318 \\
\hline New initiatives 820MW public sector peaking plant & 1000 & 400 & 600 \\
\hline Combined cycle and peaking plant:1325MW & 1500 & 375 & 1125 \\
\hline Solar and wind projects:110MW & 200 & 50 & 150 \\
\hline Coal PPP:2600MW & 4000 & 1000 & 3000 \\
\hline Total & 7.1 billion US\$ & 1925 & 5175 \\
\hline
\end{tabular}

Source: Bangladesh Development Forum 2010 
Table 3 gives information on new initiatives and expected investment for generation projects financed by public and private sectors.

Table 4 shows the estimation of total investment cost at different sectors of the electricity energy market in upcoming five to six years:

Table 4: Estimated Total Cost in next 5-6 Years

\begin{tabular}{|l|c|}
\hline Sector & Estimated Total Investment(M US\$) \\
\hline Generation & 7,000 M US \$ \\
\hline Transmission & 1,000 M US \$ \\
\hline Distribution & 1,500 M US \$ \\
\hline Total for Power & 9,500 M US \$ \\
\hline
\end{tabular}

Source: Bangladesh Development Forum 2010

By near future, Bangladesh is going to invest the huge amount of 9500M US $\$$ to the power sector.

\section{HOW THE POWER MARKeT IS LOCKeD}

Locked power market indicates a monopoly market where the government only supplies the electricity and others are consumers of it. The power market is locked mainly for following few reasons:

- The initial cost of installation is very high. Massive investment needs for the construction of a power plant. It's very difficult for people and entrepreneurs to invest this huge amount of money. On the other hand, costs for power plants are increasing day by day. So, there are a few opportunities to establish a power plant by individual initiatives.

- Required large areas which are not always available. Power station should be located at considerable distance from the populated area. Ordinary people are not able to manage such kind of large areas easily. Government has abundant demesnes and that's why it is very easy for the government to establish a power plant at any desired location throughout the country. Additionally, the government may take public land through proper procedures.

- The electric power sector is considered as public welfare sector. Nowadays, electricity is a basic need for our modern livings. So, it requires a large-scale subsidy because government considers it as a social-welfare activity.

- National Security and proper maintenance are important factors to make it unlock. Power grid is related to national security and it needs huge and proper maintenance which are important factors.

Traditional power system consists of many limitations. To continue monopoly market structure only government has to take the responsibility of power generation. But sometimes it is not possible like a country Bangladesh where the demand for electricity is far greater than the generation. Then Government has to take electric power from different private power generation companies through various agreements. This practice is very inefficient because of the high cost and inaccurate agreement. A study shows that Bangladesh government is now buying per unit $(\mathrm{kWh})$ electric power which is greater than five times than average selling rate. Following table represents per unit cost for electricity generation by peaking power plants of Bangladesh where a residential consumer has to pay at the rate of 3.33 BDT for the first 50 unit consumptions. 
Table 5: Energy buying rates from private power Generation Company per unit scale

\begin{tabular}{|l|c|c|}
\hline Name of power plant & Energy type & Per unit (BDT) \\
\hline Summit Madanganj & Diesel & 29.77 \\
\hline Desh Energy & Diesel & 25.89 \\
\hline Agrico, International & Diesel & 24.55 \\
\hline RZ Power & Diesel & 24.44 \\
\hline DPA Power Generator & Diesel & 23.89 \\
\hline Amnura (Sinha Power) & Furnace oil & 18.75 \\
\hline Northern Power & Furnace oil & 18.43 \\
\hline Raj Lanka Power & Furnace oil & 17.27 \\
\hline NEPC BD, Haripur & Furnace oil & 16.65 \\
\hline RPCL, Gazipur & Furnace oil & 16.61 \\
\hline
\end{tabular}

This paper describes a way to unlock this market where consumers also take the responsibilities of power generation and get the opportunity to invest. If the government unlocks it, the country will relieve from these unfruitful agreements by engaging common people in power market directly.

\section{Features of AN UnLocked PoWer MARKet}

Although it is difficult to unlock the whole electricity energy market if the following features are adopted, common people can easily enter into the electricity energy market.

- There should be scope for anybody to enter the market with lowest amount of money.

- Easy way to sell energy

- Easy installation of power source

- Quick installation of power source

- Easy integration with local grid

\section{Proposed Method of Power Generation and Evacuation System UTILIZING CP MODEL}

In most of the power sectors, around the use of the traditional or conventional method of power generation and evacuation system. Firstly power is generated from generation subsystem then carried by grid subsystem and from this subsystem power is flown to consumer user through distribution subsystem (Khan et al., 2015a). So there is no scope to incorporate common people to trade of $\mathrm{KWh}$ in the conventional method of power generation and evacuation system.

\section{Generation}

\section{Grid}

Distribution

\section{Normal}

\section{Consumer}

Figure 2: Conventional method of power generation and evacuation system 


\section{A brief explanation of CP Model}

The Consumer is producer (CP) model is a new technique to generate and distribute electricity with high power quality, stability, reliability and lower transmission and distribution loss thus low cost. It is designed as easier as plug and play equipment and within the shortest time, it will able to provide electricity to a large amount people. Conventional electricity generation is accomplished by large power station through transmission and distribution. The loss of transmission and distribution is enough to reduce the overall efficiency of power system (Khan et al., 2015b).

The model comprises with Consumer Producer Unit (CPU) in figure 3, Micro grid, interconnected Micro grid, and control and management unit. 10\% (10KWp) of total solar PV panel will be installed by entity a. Rest $90 \%(90 \mathrm{KWp})$ will be combined installed by all of entity b. Total 45 consumer shares of total $90 \mathrm{kWp}$ of entity b. So each consumer enter into market by providing $2 \mathrm{KWp}$ PV energy. Control measurement entity $\mathrm{b}$ is connected to every $2 \mathrm{kWp}$ solar energy source unit. Control measurement unit collect information from the source unit and recorded the supplied amount of energy to grid from source unit. Both control measurement unit of entity a and entity $b$ is connected by two way communication system.

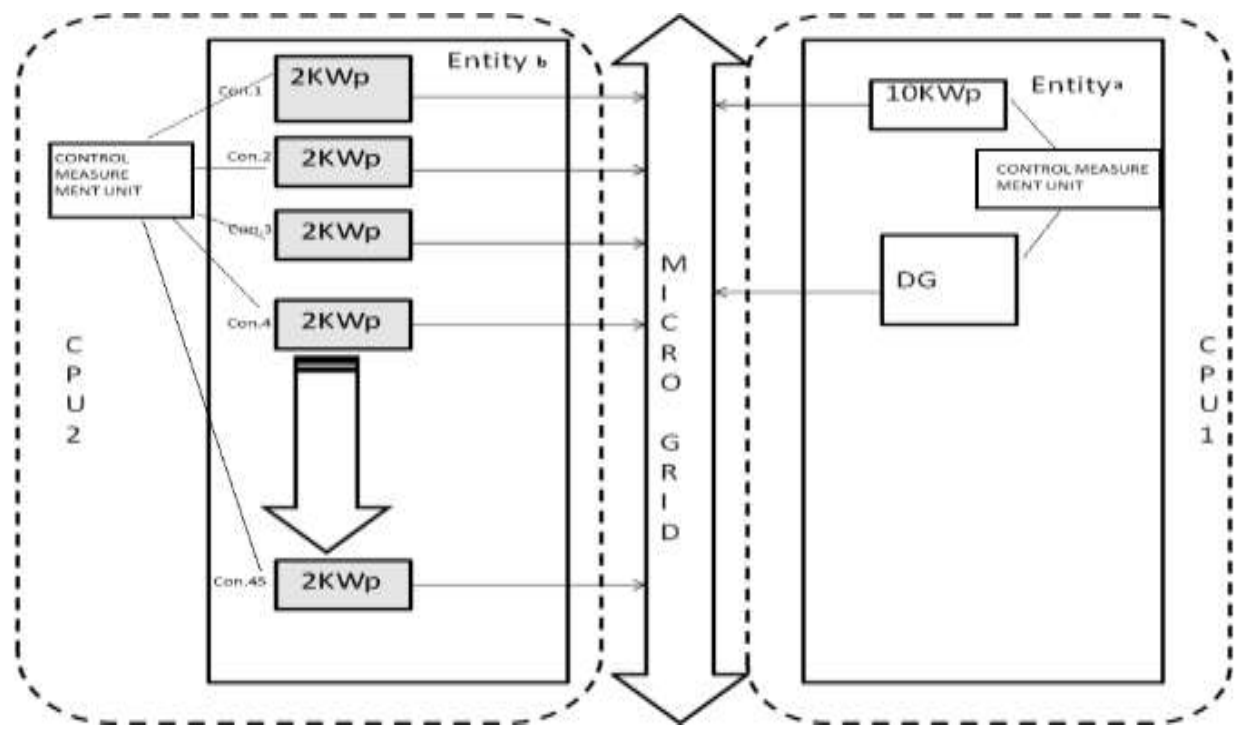

Figure 3: Block diagram of the Micro grid and CPU

\section{Mathematical model analysis of CP Model}

Firstly it is demanded as well as the number of connected CPUs (Consumer Producer Unit) will be less than that of a saturated grid. The total connected solar panel by entity a is denoted by $S_{\mathrm{p} 1}$ and entity $b$ is $\mathrm{S}_{\mathrm{p} 2}$. In this case, the total connected CPUs in the grid will be Sрт. In this stage, entity a either entity b or entity c can easily connect their CPUs when they wish. Power generated by entity $a$ and entity $b$ will be available in the grid to be consumed. A block diagram of the micro grid is shown in Fig. 3. Battery needed for this size of solar panel is В (Khan et al., 2016) whether it is served by entity a or by entity b. For easy calculation, it is assumed that the total battery needed will be installed by entity a and fuel based generators which is needed for a reliable operation. The size of the backup generator will depend on the maximum demand of the system. 
In reference of (Khan et al., 2016), it has been assumed 40 customers are connected to the grid per $\mathrm{km}$ of distribution line. For 200 users (types 2 and type 3), it needs $5 \mathrm{~km}$ distribution line and $1 \mathrm{~km}$ for interconnections of the line approximately. The number of distribution pole is assumed as around 60 (1 pole per $100 \mathrm{~m})$. There are also cost involvements for central controllers and others equipment.

Installation cost for entity amay be given by

$\mathrm{C}_{1} 1=\mathrm{CP} 1+\mathrm{CB}_{\mathrm{B}}+\mathrm{CDL}+\mathrm{CDP}+\mathrm{CFG}_{\mathrm{F}}+\mathrm{CCE}+\mathrm{C}_{\mathrm{O}}$

The total Energy sale may be given by,

$\mathrm{TS} 1=(\mathrm{EP} 1+\mathrm{EP} 2-\mathrm{EPL}+\mathrm{EDG}) \times \mathrm{S}$

The total cost per year is given by,

$\mathrm{TC} 1=\mathrm{EP} 2 \times \mathrm{B}+\mathrm{CDG}+\mathrm{CR}_{\mathrm{R} 1}$

And the net profit per year is given by,

$\mathrm{TP}=\mathrm{TS} 1-\mathrm{TC} 1$

Where,

CP1 = solar panel cost

$\mathrm{CB}=$ Battery backup cost

$\mathrm{CDL}=$ Distribution lines cost

$\mathrm{CDP}=$ Distribution poles cost

$\mathrm{CFG}_{\mathrm{FG}}=$ fuel cost

$\mathrm{C} C \mathrm{E}=$ Cost for Control equipment

$\mathrm{CO}=$ other costs (labor, land transport etc.)

$\mathrm{C}$ T1 $=$ Installation Cost.

$\mathrm{CDG}=$ fuel generator cost

EP1=Usable energy from the Panels of entity aper year

EP2=Total energy buy from entity b (Total 90KWp)

EPL=Energy loss due to battery (Charging and discharging)

EDG=Energy from DG (Assume 30\% of Total KWp

CR1=Yearly Running Cost (employee + other maintenance cost)

$\mathrm{S}=$ Selling price of entity a

$\mathrm{B}=$ Buying price of entity $\mathrm{b}$

TC1=Total Cost

The free space of rooftop of a typical village is enough to install $2 \mathrm{KWp}$ of solar panel (Newbery, 1995). In this case, there will be no additional cost for the land. The costs are associated with the solar PV panel, CPU controller and others the installation cost for each entity $b$ is given by

$\mathrm{C}_{\mathrm{T} 2}=\mathrm{CP}_{2}+\mathrm{C}_{\mathrm{CPU}}+\mathrm{C}_{\mathrm{O}}$

The total Energy sale may be expressed as

$\mathrm{TS} 2=\mathrm{EP} 2 \times \mathrm{B}$

Yearly Running Costs including employee and other maintenance cost per year is given by, $\mathrm{TC} 2=\mathrm{CR} 2$ 
And the net profit per year is given by,

TP2 $=$ TS2 - TC2

Where,

$\mathrm{CP}_{\mathrm{P} 2}=$ Cost for solar panel by entity $\mathrm{b}$

$\mathrm{CCPU}=\mathrm{Cost}$ for $\mathrm{CPU}$

$\mathrm{C}_{\mathrm{O}}=$ other costs

\section{Financial Analysis: Payback period of the initial investment of CP Model}

Initial investment for entity a may be approximated as follows. Cost and calculation has been shown based on present market value and report of Sandwip 100K Wp micro grid (Appraisal PGEL Solar Mini Grid). National Renewable Energy Laboratory (NREL) is an international renowned institution for Renewable Energy analysis it offers an online analysis named PVwatt which is open to all. Bangladeshi Taka (Tk.) is used here as unit of money. In this approximation, $10 \%(10 \mathrm{KWp})$ of total solar PV panel will be installed by entity 1 . Rest $90 \%(90 \mathrm{KWp})$ will be combined installed by all of entity $\mathrm{b}$. The analyses here are given for a $100 \mathrm{~K} \mathrm{Wp}$ solar PV micro grid investment for both of entity a and entity $\mathrm{b}$ while the selling price of entity $\mathrm{b}$ is $10 \mathrm{Tk}$ and $15 \mathrm{Tk}$. The analysis is done by MATLABprogramming environment.

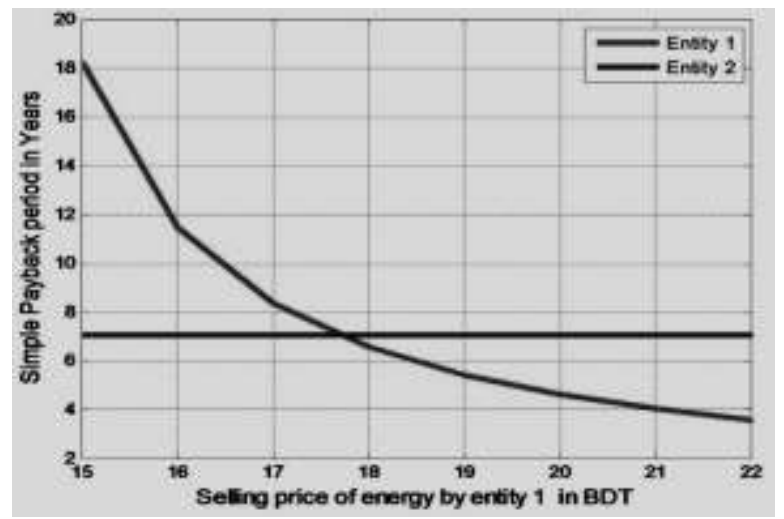

Figure 4: Payback period of the initial investment for both of entity aand entity b while the selling price of entity $b$ is $10 \mathrm{Tk}$

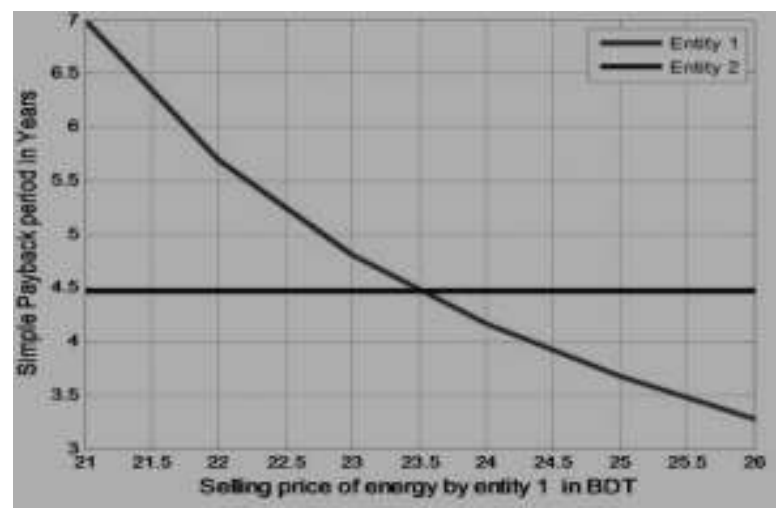

Figure 5: Payback period of the initial investment for both of entity aand entity $b$ while the selling price of entity $\mathrm{b}$ is $15 \mathrm{Tk}$ 
From the Figure 5, it is found that the payback period of the initial investment for entity $b$ is 7 years while the selling price of entity b is 10Tk. Another result shown in the Figure 6, payback period of the initial investment for entity $\mathrm{b}$ is 4.5 years while the selling price of entity b is 15 Tk. Pay-back period decreases as selling price of the entity increases. The combination of lower pay-back period and higher selling price of entity $b$ is taken to count per unit savings for buying energy of Bangladesh govt. as shown below Figure 6.

Table 6: purchase cost from differents particulars and cpu

\begin{tabular}{|l|c|c|}
\hline Particulars & Nature of Fuel & $\begin{array}{c}\text { Purchase cost per unit(kWh) from } \\
\text { public and rental and CPU }\end{array}$ \\
\hline NWPGCL(PP) & Diesel(Fuel) & 27.59 \\
\hline AGGREKO(RP) & Diesel(Fuel) & 24.55 \\
\hline DPA(RP) & Diesel(Fuel) & 23.89 \\
\hline DESH Energy(RP) & Diesel(Fuel) & 25.89 \\
\hline R Z power(PP) & Diesel(Fuel) & 24.44 \\
\hline Northern Power(PP) & HFO(Fuel) & 18.43 \\
\hline $\begin{array}{l}\text { Proposed CPU 1 } \\
\text { (10 yaer payback) }\end{array}$ & PV & $\mathbf{1 6 . 5}$ \\
\hline
\end{tabular}

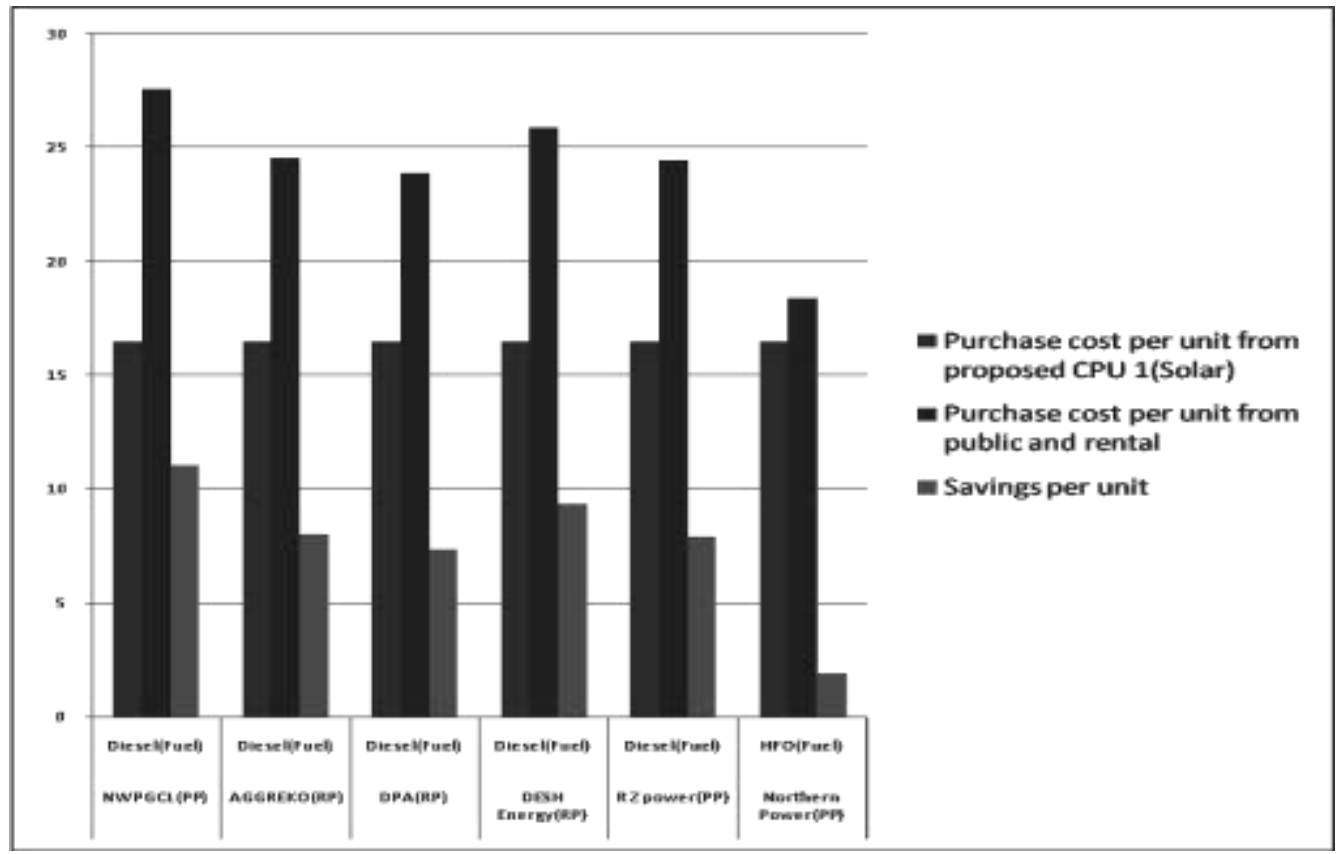

Figure 6: Savings per unit (BDT) if govt. buys energy from CPU.

Bangladesh government purchase electricity from some public sector and rental plants by per unit electricity cost varing from 27.59 to 18.43 BDT (Bangladesh Development Forum 2010). From proposed CPU per unit electricity cost from entity ais 16.5 BDT with 10 years payback period. Per unit savings is shown in Figure 6 by comparising some public and rental sector with $\mathrm{CPU}$. 


\section{POSSIBILITIES}

Consumer is Producer model is described in (Appraisal PGEL Solar Mini Grid). For convenient, it is mentioned here briefly. An applicable policy for implementing CP model has been also discussed in [8]. As the unit size proposed in (Khan et al., 2016) and is very small, the initial cost is also low as well. Most of the people can install it easily. Moreover, if there is subsidy in this model like SHS model, the installation will be painless economically. The analysis done in (Khan et al., 2016) shows that there will be a quick return of initial investment. Comparing CP model with SHS model says that there is no business interest in SHS for the customer. However, in CP model, the main interest is to incorporate common people to business of electrical energy. Thus there will be a rapid engagement of common population through this model.

\section{Conclusion}

Power market in all over the world become naturally monopoly. Monopoly market is not competitive market. One of the major reasons to become monopoly power market is unable to bear of massive initial investment. But time has come to take opportune of renewable energy. In CP model, the source of power renewable energy is used. In this paper the $\mathrm{CP}$ model is incorporated to proposed method of power generation and evacuation. A mathematical model is analyzed. A financial analysis is also performed by matlab software. The analysis shows that there will be a quick return of initial investment. So it will be opened the opportunity to engagement of common people to trade of KWh.

\section{REFERENCES}

Agelidis, V.G. Pavlovski, C. Ciobotaru, M. Tschirschwitz, T. Corke, R. Lampard, T. and Kobal, B. 2011, November. Unlocking the Smart Grid: An Australian industry-university collaborative effort to address skill gaps. In Innovative Smart Grid Technologies Asia (ISGT), 2011 IEEE PES (pp. 1-8). IEEE.

Appraisal PGEL Solar Mini Grid, "Executive Summar" of Sandwip 100 KW Microgrid.

Bangladesh Development Forum 2010, Energy and power, Dhaka, Ministry of Power, Energy \& Mineral Resources, Government of the People's Republic of Bangladesh.

Hunt, S. and Shuttleworth, G. 1996. Unlocking the grid [electricity industry restructuring]. Spectrum, IEEE, 33(7), pp.20-25.

Khan, A.H. Islam, A. Islam, M. Nur, T.E. and Ghose, S. 2015a. A Review of Electricity Generation and Evacuation in Bangladesh. Energy and Power, 5(1), pp.10-16.

Khan, A.H. Islam, A. Islam, M.S. Pial, H.H. and Rahman, M.S. 2015b, September. Consumer is producer-a novel model for electricity generation. In Green Energy and Technology (ICGET), 2015 3 rd International Conference on (pp. 1-5). IEEE.

Khan, A.H. Islam, M. Rahman, M.S. "An Applicable Implementation Policy for "Consumer is Producer" Model"(International Journal of Scientific \& Engineering Research, Volume 7, Issue 2, February-2016 ISSN 2229-5518), USA.

Newbery, D.M. 1995. Power markets and market power. The Energy Journal, pp.39-66.

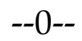

ISSN: 2409-3629

Online Archive Link: $\underline{\text { https://abc.us.org/ojs/index.php/ei/issue/archive }}$ 